\title{
SOME RESULTS OF THE PREZIOSI OPERATION*
}

BY

\author{
T. STUART-BLACK KELLY \\ Hereford
}

A SIMPLE glaucoma operation which can be consistently successful is still needed. The nearest approach to this from the point of view of ocular tension would appear to be the anterior flap sclerotomy with basal iridencleisis (Stallard, 1953), but this is a technically difficult operation requiring very great skill. After various trials with measures on the ciliary body, attention is returning to simple drainage as in the trephine but using other methods of making the filtration hole, e.g. diathermy. The Preziosi cautery method (Preziosi, 1924, 1950) appears to have been introduced originally as a safe method from the point of view of sepsis, but its general use was discontinued so long ago that it is rarely mentioned in the current text-books. The series reported here began in 1951, and the results have been so impressive that the operation has replaced nearly all previously used procedures in the writer's practice. The method is not fraught with the obvious danger of thermal cataract that immediately springs to mind, and appears to give rise to no serious complications. The anterior chamber takes some time to reform, but no massage is required, a good bleb forms, and the ocular tension remains at $25 \mathrm{~mm}$. $\mathrm{Hg}$ or less in over 90 per cent. of cases of chronic simple glaucoma.

\section{Operation}

Anaesthesia.-This may be general or local. The local anaesthetic consists of 4 per cent. cocaine, with a facial block, retrobulbar, and superior rectus injections (xylocaine and hyalase). A subconjunctival injection may be added for the first few dissections of the flap by cautery.

Method.-After the introduction of a speculum, a superior rectus suture is inserted. Reflexion of the conjunctiva follows as for a trephine, and may be done with the cautery. With the cautery, contraction of the conjunctiva might be expected, but the dissection is clean, and the whole cautery sequence is unexpectedly interesting from a surgical standpoint. The ordinary galvano-cautery point at red heat is passed through the limbus into the angle by one or more sweeps, as in an ab externo approach, until the aqueous escapes. There is no possibility of damage to the underlying structures as the aqueous cools the cautery. The puncture should be large enough to admit an iris repositor into the anterior chamber, but if not it may be enlarged with cautery or de Wecker's scissors. The iris may or may not be burnt. Should it prolapse into the puncture hole it is perforated with the cautery, and then replaced. Another method which was used at first was to use the cautery as a keratome, but this method was later abandoned because it showed no improvement on the ab externo approach. The cautery is bent to a keratome angle and may then be passed like a keratome, but more rapidly into the angle. It may

*Received for publication January 3, 1956. 
reach as far as the pupil, cooling being instantaneous. If the iris does not present it may be withdrawn and an iridectomy performed or a pillar may be brought out for inclusion. The conjunctival wound is closed, atropine and an antibiotic is instilled, and a single dressing given.

Post-operative Course.-One eye is padded. The patient may be allowed up the next day, and may be discharged as early as a week later if desired.

\section{Results}

Between 1951 and 1954, 46 eyes were operated on, 31 for chronic simple glaucoma and eleven for secondary glaucoma. The patients' ages were as follows:

41-60 yrs, 19 per cent.;

61-70 years, 35 per cent.; over 70 years, 45 per cent. There were eighteen females and 24 males.

Intra-Ocular Pressure.-The intra-ocular pressure, unless obviously low, has been taken by tonometry, $25 \mathrm{~mm}$. $\mathrm{Hg}$ or below being taken as normal. In the chronic simple cases, after a period ranging from 3 months to 3 years (average 2 years) since the operation, 93 per cent. (29) have normal tension, and five have normal tension although ceasing to drain.

In the cases of secondary glaucoma the results were varied. There were two haemorrhagic cases which were both failures. Of two aphakic cases one is satisfactory and one has not been traced. Of six cases of uveitis, only one failed.

\section{Complications}

(1) Choroidal Detachment.-This was seen in 25 per cent. of the "keratome type " but not in the ab externo type. It invariably settled down but might take a long time; in one case each eye took 9 months. It may be so large that the two sides of the retina nearly meet, but it is no contraindication to discharge. Comparison of the pre-operative and eventual post-operative fields showed no change.

(2) Hyphaema.-This never amounted to more than a few patches on the iris, and only followed a scissors iridectomy.

(3) Iris Impaction.-This may occur if there is no iridectomy, and may be seen but may cause no symptoms on the following day. The flap should be raised and the prolapse either perforated by cautery and replaced or an iridectomy performed. This happened only twice in the first few "keratome type " cases.

(4) Injury to Lens.- This occurred in one case only, through misdirection in a case of the "keratome" type. A dense white scar, the pattern of the cautery point, resulted; it gradually faded over $2 \frac{1}{2}$ years and is now difficult to see.

(5) Bleb Infection.-This happened twice in one eye and was easily controlled.

(6) Iridocyclitis.-A pigment disturbance is occasionally seen. Posterior synechiae may arise if atropine is omitted, but they may be ruptured by mydricaine. One severe case of cyclitis and rapid maturation of cataract arose some months after operation.

\section{Discussion}

In cases of simple chronic glaucoma the operation does not produce such 
good results as that of Stallard, but seems to be just as successful as any other filtration operation. It has the great advantage of simplicity and speed, and, as far as this series goes, an absence of serious complications. Aftertreatment presents no difficulties, and the patient may be allowed up the next day if desired, since there is no tendency to haemorrhage, and the reaction is slight. This is a considerable advantage in elderly patients.

Successful drainage is probably due to the hard scar ring produced by the cautery. It may contract a little but is unlikely to be as helpful to fibroblasts as a trephine hole. The histology has been dealt with by Neame (1950). There does not scem to be a marked difference in the bleb whether the flap was made by cautery or by scissors. In no case was the iris withdrawn and anchored, and it is felt that this might have helped with the failures. If not anchored, the iris might slip back through the open cautery sclerotomy. In some of the cases in which drainage ceased but a normal ocular tension remained, the marked choroidal detachment suggests some beneficial damage to the ciliary body.

Failures occurred in cases in which other operations had also failed, one patient having previously had a cyclodialysis, iridencleisis, and trephine, another a sclerotomy and an anterior flap sclerotomy with basal iridencleisis.

Thermal cataract is no doubt one of the reasons for avoiding the operation, but this can only happen in the "keratome type", for this reason, the $a b$ externo type is the method of choice.

\section{Summary}

In this small series the Preziosi method was found to be a simple and easy filtration operation for chronic simple glaucoma, draining satisfactorily in 80 per cent., and the tension being reduced to normal in a further 10 per cent. which had ceased to drain.

With the ab externo method there appears to be no serious complications. Since post-operative care is minimal and haemorrhage negligible, it is particularly suitable for elderly patients.

In secondary glaucoma the results are poor in haemorrhagic cases but good in uveitis.

Although no acute cases are listed, this operation is now the method of choice in the author's practice for all cases except those in which a cyclodialysis or cyclodiathermy is thought to be essential.

\section{REFERENCES}

Neame, H. (1950). “ “XVI Int. Conc. Ophthal. 1950 Britannia Acta ”, vol. 2, p. $975 . \quad$ B.M.A., London.

Preziosi, L. (1924). British Journal of Ophthalmology, 8, 414.

(1950). "XVI Int. Conc. Ophthal. 1950 Britannia Acta", vol. 2, p. 971, B.M.A., London.

Stallard, H. B. (1953). British Journal of Ophthalmology, 37, 680. 